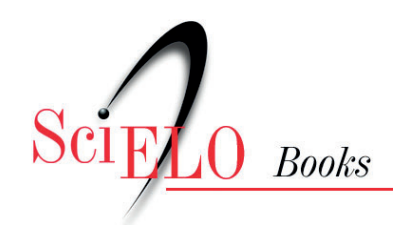

\title{
3. Educação profissional integrada à educação de jovens e adultos - Proeja inéditos viáveis da Rede Federal de Educação Profissional, Científica e Tecnológica
}

\author{
Simone Valdete dos Santos \\ Janaína Marques Silva \\ Margarete Maria Chiapinotto Noro
}

\section{SciELO Books / SciELO Livros / SciELO Libros}

SANTOS, S.V., SILVA, J.M., and NORO, M.M.C. Educação profissional integrada à educação de jovens e adultos - Proeja: inéditos viáveis da Rede Federal de Educação Profissional, Científica e Tecnológica. In: PAIVA, J., comp. Aprendizados ao longo da vida: sujeitos, políticas e processos educativos [online]. Rio de Janeiro: EDUERJ, 2019, pp. 67-77. Pesquisa em educação/Educação ao longo da vida series. ISBN: 978-65-990364-9-1. https://doi.org/10.7476/9786599036491.0004.

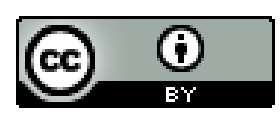

All the contents of this work, except where otherwise noted, is licensed under a Creative Commons Attribution 4.0 International license.

Todo o conteúdo deste trabalho, exceto quando houver ressalva, é publicado sob a licença Creative Commons Atribição $\underline{4.0}$.

Todo el contenido de esta obra, excepto donde se indique lo contrario, está bajo licencia de la licencia Creative Commons $\underline{\text { Reconocimento } 4.0 .}$. 
3

\title{
Educação profissional integrada à educação de jovens e adultos - Proeja: inéditos viáveis da Rede Federal de Educação Profissional, Científica e Tecnológica
}

\author{
Simone Valdete dos Santos \\ Janaína Marques Silva \\ Margarete Maria Chiapinotto Noro
}

\section{Introduçáo}

O Programa Nacional de Integração da Educação Profissional com a Educação Básica na Modalidade de Educação de Jovens e Adultos (Proeja), instituído pelo Decreto Lei n. 5.840 de 2006, compóe a meta 10 do Plano Nacional de Educação - Lei n. 13.005/2014: “[...] oferecer, no mínimo, 25\% (vinte e cinco por cento) das matrículas de educação de jovens e adultos, nos ensinos fundamental e médio, na forma integrada à educação profissional”.

Constituem estratégias relacionadas ao Proeja, conforme a Lei n. 13.005/2014, para o cumprimento da meta 10 do PNE: 
[... 10.3) fomentar a integração da educação de jovens e adultos com a educação profissional, em cursos planejados, de acordo com as características do público da educação de jovens e adultos e considerando as especificidades das populaçóes itinerantes e do campo e das comunidades indígenas e quilombolas, inclusive na modalidade de educação a distância;

[...] 10.6) estimular a diversificação curricular da educação de jovens e adultos, articulando a formação básica e a preparação para o mundo do trabalho e estabelecendo inter-relaçóes entre teoria e prática, nos eixos da ciência, do trabalho, da tecnologia e da cultura e cidadania, de forma a organizar o tempo e o espaço pedagógicos adequados às características desses alunos e alunas;

10.7) fomentar a produçáo de material didático, o desenvolvimento de currículos e metodologias específicas, os instrumentos de avaliação, o acesso a equipamentos e laboratórios e a formação continuada de docentes das redes públicas que atuam na educação de jovens e adultos articulada à educação profissional;

[...] 10.11) implementar mecanismos de reconhecimento de saberes dos jovens e adultos trabalhadores, a serem considerados na articulação curricular dos cursos de formaçáo inicial e continuada e dos cursos técnicos de nível médio.

As estratégias orientam o mapeamento de inéditos viáveis ${ }^{1}$ na educação de jovens e adultos (EJA), conforme a perspectiva teórica de Paulo Freire, sobretudo no entendimento de trabalho para as comunidades indígenas e seu envolvimento com o mesmo; nos currículos específicos para a formação de jovens e adultos por área do conhecimento articulados à educação profissional; no reconhecimento de saberes de jovens e adultos trabalhadores de modo que inspirem e potencializem os currículos escolares.

O Proeja também se inclui nestes inéditos viáveis, especialmente pela sua presença na Rede Federal de Educação Profis-

1. Conceito presente especialmente na obra de Paulo Freire Pedagogia da Esperança. 
sional, Científica e Tecnológica, tendo em vista a educação de excelência que essa rede possui, contando com mestres e doutores em seu corpo docente e uma infraestrutura adequada.

\section{O Proeja na Rede Federal de Educaçáo Profissional, Científica e Tecnológica}

A importância de refletirmos sobre o êxito de programas como o Proeja ocorre em função da demanda expressiva de pessoas jovens e adultas por elevaçáo de escolaridade em cumprimento da meta 10 do PNE.

A média da alfabetização no Brasil é de 90,3\%. Quase a metade da população acima de 25 anos (49,5\%) tem pelo menos o ensino médio - aproximadamente doze anos de estudo. Essas sáo conquistas importantes da educação brasileira dos últimos vinte anos. No entanto, ainda cerca de 50 milhóes de pessoas ${ }^{2}$ com dezoito anos ou mais requerem educação básica - ensino fundamental e ensino médio - , uma vez que necessitam trabalhar ou qualificar seu trabalho.

Tal público é foco da Rede Federal de Educação Profissional, Científica e Tecnológica, que foi ampliada nos últimos dez anos. A Rede é composta pelos Institutos Federais de Educação, Ciência e Tecnologia (IF), Centros Federais de Educação Tecnológica (CEFET), Escolas Técnicas vinculadas às Universidades Federais, Universidade Tecnológica Federal do Paraná, Colégio Pedro II e Escolas Agrotécnicas Federais, totalizando 644 unidades no país inteiro. Sua origem remonta a 1909, com a criação de Escolas de Aprendizes e Artífices. A institucionalização da Rede Federal decorre da Lei n. 11.892 de dezembro de 2008, compondo prerro-

2. Dados do último Censo populacional - Instituto Brasileiro de Geografia e Estatística (IBGE) 2010 . 
gativa do Artigo $8 .^{\circ}$ a oferta de 50\% das matrículas em educação profissional técnica de nível médio, prioritariamente na forma de cursos integrados para os concluintes do ensino fundamental e para o público da educação de jovens e adultos.

O Documento Base ${ }^{3}$ do Proeja traz consideraçóes norteadoras envolvendo o contexto em que os sujeitos dessa modalidade de ensino constroem suas vidas enquanto trabalhadores formais, informais, empregados, autônomos ou desempregados. Eles são “[...] portadores de saberes produzidos no cotidiano e na prática laboral. Formam grupos heterogêneos quanto à faixa etária, conhecimentos e ocupação (trabalhadores, desempregados, atuando na informalidade)" (Brasil, 2007, p. 45).

Além de serem estudantes que trabalham, muitos jovens adultos da EJA já constituíram família, portanto experimentam uma longa e dupla jornada estudo/trabalho, que os afasta do convívio familiar. Os motivos pelos quais náo conseguiram acessar o ensino regular na idade recorrente estáo, na sua grande maioria, relacionados a fatores de ordem social, que promoveram desvios nas suas temporalidades e intencionalidades pessoais, incompatibilizando suas trajetórias de vida com os percursos escolares que lhes foram oferecidos (Brasil, 2007, p. 45).

Logo, esses estudantes da EJA em algum momento foram excluídos da escola ou nunca a frequentaram, desafiando o entendimento de uma educação para todos e todas, contrariando o direito à educação, questionando os modos de ser da escola, questionando a "ordem" escolar.

A compreensão da EJA vinculada a um movimento de "desordem", diante dos pressupostos de "ordem" da escola, é fundante na análise, sendo Balandier (1997, p. 235) seu principal teórico:

3. Marco conceitual e regulatório do Proeja (2007) que orientou a implantação dos cursos em várias instituições da Rede Federal de Educação Profissional, Científica e Tecnológica. 
Aplica-se a encontrar a ordem escondida na desordem, a estabelecer uma relaçáo menos desconfiada com o aleatório, a propor uma nova compreensão do imprevisível. Consegue assim produzir uma descrição do mundo onde a consideraçáo dos dinamismos, do movimento, dos processos toma a dianteira sobre as permanências, as estruturas e as organizaçôes.

O estudante da EJA trabalha, contribui ou até é responsável pelo sustento familiar. Tem, ainda, horários de estudo e valores atribuídos às aprendizagens com motivações específicas e embasadas em suas experiências. Constitui o que Balandier (1997, p. 103) nomeia como figuras de desordem, figuras reveladoras:

A desordem e o caos não estão somente situados, estão exemplificados: à topologia imaginária, simbólica, associa-se um conjunto de figuras que manifestam sua ação dentro do próprio espaço policiado. Figuras ordinárias, no sentido de que se encontram banalmente presentes dentro da sociedade, mas em situação de ambivalência por aquilo que é dito delas e aquilo que elas designam. Complementar e subordinadamente, elas são o outro objeto de desconfiança e de medo em razão de sua diferença e de seu status inferior, causa de suspeita e geralmente vítima de acusação.

Os estudantes da EJA como figuras de desordem na ordem escolar promovem outras experiências educativas, na contramão da evasão e do fracasso escolar, os quais são lugar comum, ordem na EJA. Altos índices de evasão e abandono constituem fato recorrente nesta modalidade de ensino com inúmeras pesquisas no campo da educação. Isso nos instiga a investigar, com a mesma relevância dada aos fatores que contribuíram para a evasão e o abandono, os motivos que possibilitaram que outros sujeitos conseguissem concluir o seu percurso formativo com sucesso. A fim de aprofundar as razóes do sucesso, seus significados e seus 
alcances na vida de cada egresso, faz-se necessário buscar nas concepçóes de bases psicossociais e educacionais pressupostos para compor um campo teórico-metodológico.

\section{Aprendizagens significativas e experiências curriculares criativas: o cotidiano do Proeja}

O Curso Técnico em Administração Proeja do Instituto Federal de Educação, Ciência e Tecnologia Sul Rio-Grandense campus Sapucaia do Sul ${ }^{4}$ completa dez anos de existência em 2017, sendo considerado uma experiência bem-sucedida não só por sua longevidade, mas também pelos resultados qualitativos e quantitativos atingidos.

Ao longo do tempo, o curso passou por adequaçóes em seu projeto inicial e, consequentemente, na sua organização curricular, motivadas pelas especificidades contidas no ser dos/das estudantes da EJA, que retornam aos estudos depois de adultos, "[...] protagonistas de histórias reais e ricos em experiências vividas" (Brasil, 2007, p. 4).

No curso em questão, com duração de três anos e organizado em seis semestres, a práxis pedagógica vivenciada na disciplina Iniciação à Formação Profissional, denominada Projeto Integrador, visa incorporar, ao ensino curricular obrigatório, conhecimentos e práticas que provoquem nos/nas estudantes a sensibilizaçáo para açóes que articulem, num exercício interdisciplinar, conhecimentos técnicos e gerais e práticas cooperativas e solidárias.

De forma coletiva, unindo técnicas de elaboração de projetos, trabalho em equipe e outras áreas do conhecimento da formação geral, os/as estudantes desenvolvem e implementam um projeto

4. A experiência do Proeja no Campus Sapucaia do Sul já foi investigada nos estudos de: Godinho (2012); Noro (2011); Siqueira (2010); Sydow (2012). 
social, em instituição de sua escolha, a partir de pesquisa de campo na comunidade, que identifica quais instituiçóes se encontram em maior situação de vulnerabilidade e necessidade de melhorias. Ao longo de um semestre, temporalidade da disciplina, os alunos planejam, desenvolvem, executam, avaliam e refletem sobre as açóes, aplicando os conhecimentos abordados nas aulas e expressando essas etapas em processos descritivos - relatórios, memoriais de reunião, entre outros.

A metodologia implementada para o Projeto Integrador ${ }^{5}$ contém seis etapas:

1. sensibilização da turma: brainstorming para escolha da instituição parceira, nome do projeto e eixos de trabalho;

2. formação de equipes de trabalho para cada eixo: estrutura física, suprimentos e relaçóes humanas;

3. diagnóstico organizacional para identificar necessidades da instituição para definir eixo de trabalho;

4. elaboração de Plano de Ações;

5. execução do Plano de Açóes;

6. avaliação coletiva do processo e dos resultados do projeto.

Desde que a disciplina passou a fazer parte do currículo, mais de dez projetos já foram desenvolvidos. Como ilustração prática, um deles, intitulado Projeto Integrador Fazendo Crianças Sorrir — crianças amadas hoje, adultos felizes amanhá, foi realizado junto a uma organização não governamental (ONG) de caráter filantrópico, que acolhe crianças de zero a dezesseis anos de forma provisória em Sapucaia do Sul e que, à época, abrigava 46 crianças em situação de risco, ali acolhidas e cuidadas por quatorze

5. Disponível em http://portal.mec.gov.br/component/content/?view=209:noticias\&id=15815:projeto-beneficia-instituicao-que-atende-menores-em-risco. Acesso 20 jun. 2017. 
funcionários. A partir de diagnóstico organizacional, foram detectadas necessidades da instituição em relação a três eixos: estrutura física, suprimentos e relaçóes humanas. Foi elaborado e executado um plano de açóes que envolveu intervençóes dos estudantes e de professores, com a finalidade de arrecadar roupas, materiais de higiene pessoal, brinquedos, fraldas descartáveis, alimentos náo perecíveis, materiais de limpeza e material escolar, na escola e na comunidade. Estudantes da turma, exercitando saberes já trazidos para o curso, executaram a reforma e a pintura de duas casas de boneca. Com a orientação de professores, também realizaram com as crianças atividades de recreação, contação de histórias e oficinas de confecção de brinquedos a partir de garrafas PET. Todas essas açóes ocorreram aos sábados, computadas na carga horária como saídas de campo.

Os resultados das experiências desenvolvidas no Projeto Integrador abrangem os seguintes aspectos: vivência discente/docente em projeto social na perspectiva de debate sobre a desigualdade social e a política de intervenção em dimensóes, envolvendo aspectos socioeconômico-culturais; reflexáo sobre a teoria e a prática de conteúdos nas organizações nos campos da Administração, Qualidade de Vida, Pesquisa Social e Intervençóes Possíveis; desenvolvimento de espaços de trabalho em parceria com outros segmentos da sociedade, aumentando a capacidade do campus em articular-se com os demais atores da sociedade; socialização de experiências possibilitando ampliar a visão de trabalho.

O contexto dessa experiência curricular possibilita aos envolvidos a ampliação da visão crítica e integrada dos conhecimentos, instigando a criatividade, adaptação e identificação de oportunidades, contribuindo para uma formação integrada. Além disso, provoca análise reflexiva acerca de um cotidiano correlacionado ao seu, seja pelas similaridades ou pelas diferenças.

A “[...] reflexividade implica que qualquer descrição seja referência a algo, mas, ao mesmo tempo, faça parte deste algo" (Pais, 
2007 , p. 28). Neste sentido, as produções descritivas das práticas educativas do projeto integrador realizado em contextos extraescolares permitem que a reflexividade discente não seja avaliada apenas por seu caráter descritivo. De acordo com Pais (2007), tais práticas educativas são açóes sociais que podem ser relevantes, numa perspectiva de ressignificaçáo que os sujeitos da EJA fazem das suas próprias trajetórias.

As intervençóes sociais, oportunizadas pelos projetos integradores nas comunidades com as quais a maioria dos estudantes mantém laços estreitos, podem contribuir para a constituição de um coletivo mais solidário e voltado para a qualidade de vida de seus pares, aprimorando conceitos de cidadania, emancipação social e aprendizagem coletiva.

Para a perspectiva freireana, o projeto educativo é também um projeto libertador e as açóes educativas se dão também como denúncia das situações de dominação, reafirmando a capacidade criadora de todo ser humano. "Daí a necessidade de atuar sobre a realidade social para transformá-la, ação que é interação, comunicação, diálogo. Educador e educando, os dois seres criadores libertam-se mutuamente para chegarem a ser, ambos, criadores de novas realidades" (Freire, 1979, p. 8).

Tal experiência curricular possibilita não só externalizar e ressignificar os conhecimentos, de forma reflexiva, existentes em muitas trajetórias de vida dos estudantes jovens e adultos trabalhadores, mas também considerar: “[...] na legitimidade pedagógica informações úteis à formulação das generalizações necessárias ao 'desenho' dos textos das políticas oficiais" (Oliveira, 2013, p. 380), contrapondo-se, por vezes, às lógicas que o sistema capitalista naturalizou como hegemônicas, mas que as reflexóes oportunizam entendê-las como opçôes sociais que podem ser desconstruídas e reconstruídas em outras lógicas percebidas, as quais nomeamos como contra-hegemônicas: inéditos viáveis. 
Numa perspectiva freireana, o projeto educativo como projeto libertador denuncia situaçóes de dominação, pela criação e recriação de açóes contra-hegemônicas - sentido maior do Proeja, política pública educacional essencial em um país que é uma das dez maiores economias do mundo.

\section{Referências}

BRASIL. Cadernos EJA 1: Trabalhando com a educação de jovens e adultos Alunas e Alunos de EJA. Brasília: MEC/SECAD, 2006. Disponível em: http://portal.mec.gov.br/secad/arquivos/pdf/eja_caderno1.pdf. Acesso em 16 jun. 2017.

BRASIL. Ministério da Educação. Programa de Integração da Educação Profissional Técnica de Nível Médio Integrada ao Ensino Médio na Modalidade de Educação de Jovens e Adultos - Proeja. Documento Base. Brasília, Distrito Federal: MEC, 2007. Disponível em http://portal.mec.gov.br/ setec/arquivos/pdf2/proeja_medio.pdf. Acesso em 16 jun. 2017.

. "Lei n. 13.005, de 25 de junho de 2014". Aprova o Plano Nacional de Educação (PNE) e dá outras providências. Brasília: Câmara dos Deputados: Edição Câmara, 2015.

BALANDIER, Georges. A desordem: elogio do movimento. São Paulo: Bertrand Brasil, 1997.

FREIRE, Paulo. Pedagogia da Esperança. São Paulo: Paz e Terra, 1997. . Conscientização teoria e prática da libertação: uma introdução ao pensamento de Paulo Freire. Sáo Paulo: Cortez \& Moraes, 1979.

GODINHO, Ana Cláudia. A experiência escolar na Educação Profissional integrada à EJA: relaçôes de saber de estudantes mulheres em sala de aula (tese). Unisinos, 2012.

NORO, Margarete Maria Chiapinotto. Gestão de processos pedagógicos do Proeja: razão de acesso e permanência (dissertação). UFRGS, 2011.

OLIVEIRA, Inês Barbosa de. "Currículo e processos de aprendizagem ensino: políticas práticas educacionais cotidianas”. Currículo sem Fronteiras, v. 13, n. 3, pp. 375-91, set./dez. 2013. 
PAIS, José Machado. "Cotidiano e reflexividade". Educação e Sociedade. Campinas, v. 28, n. 98, pp. 23-46, jan./abr. 2007. Disponível em: http:// www.cedes.unicamp.br/.

SIQUEIRA, André Boccasius. Alunos do Proeja: Histórias de estudantes do Instituto Federal de Educação Ciência e Tecnologia Sul-Rio-Grandense Campus Sapucaia do Sul (tese). Unisinos, 2010.

SYDOW, Bernhard. Currículo integrado do Proeja (dissertação). UFRGS, 2012. 